\title{
Immune Mechanisms in Autoimmune Ocular Disease
}

\author{
S. LIGHTMAN \\ London
}

\begin{abstract}
Summary
Aberrant expression of Class II MHC antigens (Ia) by non-immune cells is considered to be an important mechanism in the pathogenesis of autoimmune disease processes including those affecting the eye. It is suggested that circulating autoreactive $T$-cells are directed to their target organ as a result of aberrant expression of Ia antigens by the vascular endothelium of that organ. This hypothesis was tested in this study using two different models of severe ocular inflammation, induced by either S-antigen or bovine serum albumin (BSA). The retinal vascular endothelium becomes $\mathrm{Ia}+$ in $\mathrm{S}$-antigen induced inflammation but not in inflammation induced by BSA. The accumulation in the eye of a $\mathrm{T}$-cell line, ThS, specific for an ocular antigen (S-antigen), was compared in the two types of ocular inflammation and compared to that of another T-cell line, ThP, specific for a non-ocular antigen (PPD). In S-antigen induced inflammation, there was much greater accumulation of ThS than ThP whereas in BSA induced inflammation, both $T$-cell lines accumulated to the same extent but more than in uninflamed eyes. These results suggest that when the retinal vascular endothelium expresses Ia antigens during an inflammatory process, autoreactive $T$-cells will be specifically retained in the eye as a result of this and perpetuate the autoimmune destructive process.
\end{abstract}

Autoimmunity is thought to be the cause of pathology in many organs in the body. ${ }^{1}$ The initiating event in autoimune disease remains elusive but it is likely that genetic, immunologic and viral factors are involved and interact through complicated mechanisms still poorly understood.

The inflammatory infiltrate in organ-specific autoimmune disease is essentially mononuclear in character and this has been taken as involvement of the cellular arm of the immune response. The huge repertoire of the immune system, necessary to allow us to recognise and react to almost any foreign molecule entering the body, has been unable to avoid the generation of lympocytes which react with the body's own constituents. ${ }^{2}$ Autoreactive B and T-cells are present in normal individuals ${ }^{3,4}$ but autoimmune disease is rare so that in most people these cells are unresponsive. It is assumed that the key to the system is the autoreactive T-helper/ inducer cell and these cells are normally unresponsive presumably as a result of either suppressive factors or failure of autoantigen presentation. The majority of organ-specific autoantigens normally appear on the surface of the cells of the target organ together with class I but not class II MHC molecules. As such, they are unable to communicate with T-helper cells (which need to see antigen in the context of class II MHC antigens in order to respond) and are therefore immunologically silent.

A potential mechanism which may be of central importance, particularly in the development of organ-specific destructive autoimmunity, is the aberrant expression of ciass II MHC molecules by target cells in organs affected by the autoimmune process. 
Bottazzo et al. ${ }^{5}$ hypothesised that if these target organ cells could synthesise class II MHC molecules, their cell surface molecules could become antigenic. Whether this is actually an initiating factor is not known but its potential for promoting pathogenesis both early and late in the process is clear.

The Major Histocompatibility Complex (MHC) encodes two major groups of cell surface proteins, known as Class I and Class II (Ia) antigens. Class I antigens are expressed on almost all cells in man (except red blood cells and nervous tissue) whereas Class II antigens (Ia) are much more limited in their distribution and were originally described on cells which have a known role in the immune system such as macrophages, monocytes, Langerhans cells and dendritic cells. ${ }^{6}$ These cells process antigen and express part of it on their surface, associated with the Ia molecules, for the purpose of presentation to and activation of T-helper cells. ${ }^{7}$ An important new finding to emerge from immunohistochemical studies is that the expression of Ia antigens is not confined to cells with a known immunological role. ${ }^{8}$ Ia can be expressed on non-lymphoid cells such as endothelial and epithelial cells and fibroblasts from a variety of organs.

Both the aetiology and effector mechanisms in organ-specific autoimmunity remain elusive. Much of the work on this subject has been done using autoimmune thyroiditis of different types, both in human disease states and in animal models. Observations in autoimmune thyroiditis ${ }^{9}$ led to the hypothesis that inappropriate expression of Class II antigens by epithelial cells might enable these cells to present their own surface molecules to auto-reactive T-cells, bypassing the need for classical antigen-presenting cells such as the macrophage. ${ }^{5}$ It has been shown that $\mathrm{T}$-helper cells can recognise Class II molecules on non-traditional antigen-presenting cells and that this recognition results in activiation of the T-cell. ${ }^{10}$ For example, thyrocytes are able to present their own autoantigens to autoreactive T-cells infiltrating the diseased thyroid. ${ }^{11}$

Much less is known about immune mediated diseases affecting the eye than the thyroid gland. This is explained in part by the very limited access to human diseased ocular tissue. Increased MHC Class II (termed HLA/DR in man) antigen expression in ocular tissue has been demonstrated to occur in vivo in man, in vitro and in experimental models of ocular inflammation. In human eyes, enucleated for a severe inflammatory disorder thought to be of autoimmune origin (uveitis), RPE cells which do not normally express HLA/DR can be demonstrated to have become HLA/DR positive. ${ }^{12}$ In retinitis pigmentosa, in which some observers have found subtle immunological changes, the RPE cells have again been found to express HLA/DR. ${ }^{13}$

Much of the experimental work has been done on ocular disease induced in rats by immunisation with a soluble retinal antigen (S-antigen, 14) which results in severe bilateral ocular inflammation. ${ }^{15}$ This animal model (experimental autoimmune uveoretinitis EAU) mimics some of the features of inflammatory eye disease seen in man $^{16}$ and is regarded as a model of immunemediated ocular inflammatory disease. The experimental evidence suggests that EAU is primarily a T-cell mediated disorder since it can also be induced by the transfer of sensitised $T$ cells, but not serum, to unimmunised recipients. ${ }^{17,18}$

In the normal rat eye, which has many similarities to the human eye, Class II antigens (Ia) are not expressed on any of the cells but when the inflammatory process of EAU is initiated, the eye becomes infiltrated by $\mathrm{T}$ cells and Ia can be shown to be expressed on the retinal vascular endothelium (RVE) (Fig 1), the RPE and the epithelium of the ciliary body (CBE). ${ }^{19,20}$

Recently, it has been demonstrated that many of the histological features of S-antigen induced disease in the rat, including photoreceptor loss, can be reproduced by immunising the rat with a non-ocular antigen (bovine serum albumin BSA) and subsequently inducing inflammation in the eye by injecting BSA into the vitreous. ${ }^{21} \mathrm{~T}$-cells were found to be infiltrating throughout the inflamed eye as found in S-antigen induced ocular inflammation. Examination of the expression of Ia antigens during BSA induced inflammation showed that the ciliary body epithelium 


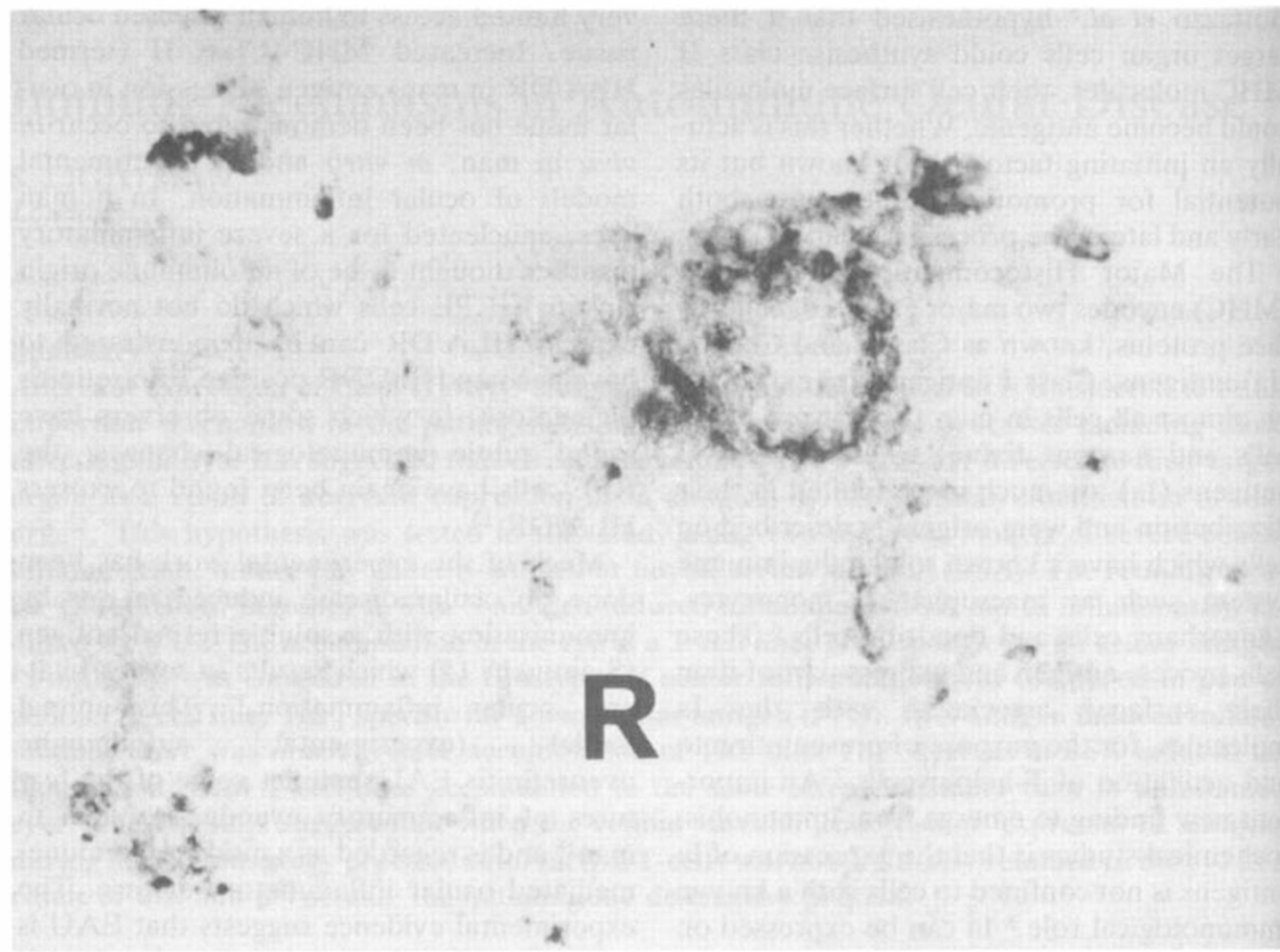

Fig. 1. Retinal capillary in a rat with EAU stained for Ia antigens by immunoperoxidase techniques with monoclonal OX6 antibody. X $1200 R=$ retina (Courtesy of $\operatorname{Dr} C$ Chan)

(CBE) and the RPE but not the retinal vascular endothelium ( $\mathrm{RVE}$ ) became $\mathrm{Ia}+.22$

Using these two models of ocular inflammation, the accumulation of two T-cell lines was examined, one of which was specific for the S-antigen and the other for an irrelevant non-ocular antigen (PPD), to see if expression of Ia antigens by the RVE was involved in binding and directing autoreactive T-cells. Uveitis was induced with either S-antigen or BSA and the rats were given ${ }^{51} \mathrm{Cr}$-labelled $\mathrm{T}$ cells IV at the peak of the inflammatory process; day 11 post immunisation with S-antigen and 24 hours post-intravitreal injection of BSA given, 10 days after systemic immunisation with BSA. The cells were allowed to circulate for 24 hours when the animal was killed and the amount of radioactivity counted in each eye. The presence of inflammation in each eye was confirmed histologically after counting. The results are correlated with the known differential expression of Ia antigens by the RVE in the two inflammatory processes and the significance of this in terms of perpetuation of the autoimmune disease process is discussed.

\section{Material and Methods}

Animals:

Six - eight week old female Lewis rats (Charles River, Raleigh, NC) were used for all experiments, both as donor and host. All procedures were carried out on rats anaesthetised with ketamine (Parke-Davis NJ) and xylazine (ICN Immunologicals, Lisle, I11.) in a 7:3 mixture, injected intramuscularly and in accordance with the ARVO resolution on the use of animals in research.

\section{Induction of uveitis with $S$-antigen (EAU):}

Rats were immunised in both footpads with $50 \mu \mathrm{g} / \mathrm{rat}$ of purified bovine $\mathrm{S}-\mathrm{Ag}^{23}$ in a $1: 1$ emulsion in complete Freund's adjuvant (CFA, Gibco Laboratories, Grand Island, 
NY) supplemented with mycobacterium tuberculosis (strain $\mathrm{H} 37 \mathrm{Ra}$ ) to give a final concentration of $2.5 \mathrm{mg} / \mathrm{ml}$. Each animal was also given $5 \times 10^{9}$ Bordetella pertussis organisms (Pasteur Institute, Paris) in $1 \mathrm{ml}$ of suspension intraperitoneally. The animals were left for 11 days, at which time severe bilateral intraocular inflammation had occurred.

\section{Induction of uveitis with BSA:}

Rats were immunised in both footpads with bovine serum albumin (BSA) in endotoxin free saline, $600 \mu \mathrm{g} / \mathrm{rat}$ in a $1: 1$ emulsion with complete Freund's adjuvant. After 10 days the rats were anaesthetised and $60 \mu \mathrm{g}$ of BSA in endotoxin-free saline was injected in $10 \mu \mathrm{l}$ into the vitreous cavity of the right eye, through the pars plana, without causing intraocular damage. $10 \mu \mathrm{l}$ of endotoxin-free saline alone was injected into the vitreous cavity of the left eye. The animals were left for 24 hours, at which time the right eyes were acutely inflamed, and the left eyes remained quiet.

\section{Selection and propagation of $T$ cell lines:}

Long term T-helper lymphocyte lines, one responding to $\mathrm{S}$ antigen (ThS) and the other to PPD (ThP), were used. These were generated from the lymph nodes of immunised Lewis rats as previously described. ${ }^{18}$ The cells used in all the experiments were aliquots of a single frozen batch, which had been in continuous tissue culture for less than two months. For each experiment, an aliquot of cells was rapidly defrosted and resuspended in RPMI 1640 medium (Gibco), supplemented as previously described. The cells were divided once after 24 hours and then allowed to rest for 4 days before being stimulated to proliferate with Con-A and thymocytes.

\section{Stimulation of $T$ cell lines:}

Prior to transfer, the cells were stimulated with Con-A with irradiated thymocytes as filler cells. ${ }^{18}$ In brief, the $\mathrm{T}$ cell lines were washed, resuspended at $1.5-2 \times 10-5 / \mathrm{ml}$ with irradiated thymocytes $(3000 \mathrm{R}, 4 \times 106 /$ $\mathrm{ml})$ and Con-A $(5 \mu \mathrm{g} / \mathrm{ml})$ in $50 \mathrm{ml}$ flasks, and incubated for 60 hours at $37^{\circ} \mathrm{C}$ in a $5 \% \mathrm{CO}_{2}$ atmosphere. Activated cells were separated from thymocyte debris by density centrifugation over Ficoll (Isolymph, GallardSchlesinger, Carle Place, NY) and then washed several times to remove the Ficoll.

\section{Chromium labelling of $T$ cells:}

$\mathrm{T}$ cells were resuspended in fresh medium at $2 \times 10^{7} / \mathrm{ml}$ and incubated with ${ }^{51}$ Chromium (as sodium chromate, specific activity $=200$ $900 \mathrm{Ci} / \mathrm{g}$ : New England Nuclear, Boston, MA), $1 \mathrm{mCi} / 10^{8}$ cells for one hour at $37^{\circ} \mathrm{C}$. The cells were then washed three times, counted and resuspended in phosphate buffered saline (PBS).

Adoptive transfer of ${ }^{51} \mathrm{Cr}$ labelled $\mathrm{T}$ cells: Approximately $10 \times 10^{6} \mathrm{~T}$ cells, specific for either S-antigen (ThS), or for PPD (ThP), were suspended in $300 \mu \mathrm{l}$ PBS and injected into the tail veins of anaesthetised host rats. Three groups of rats were used: control rats (no inflammation), rats with S-antigen induced uveitis (day 11) and rats with BSA induced uveitis (24 hours after intravitreal injection). An aliquot of the labelled cells was counted in a gamma counter (Beckman) to determine ${ }^{51} \mathrm{Cr}$ uptake per cell. Twenty-four hours later, the rats were killed and the eyes removed. The eyes were placed into $10 \%$ formaldehyde (formalin) prior to gamma-counting and subsequently processed for histologic examination. The results are expressed as the estimated accumulation of labelled cells per eye $^{24}$ as follows:

estimated accumulation/eye $=$

(cpm in eye - background $\mathrm{cpm}) \times$ number of cells injected

(cpm of cells injected - background cpm)

\section{Results}

Retention of ThS and ThP in uninflammed eyes

Small numbers of both $\mathrm{T}$-cell lines were found in the eyes of normal rats. There was no difference in the estimated numbers of ThS and ThP in these eyes (Fig 2).

Retention of ThS and ThP during actively induced EAU:

Ten animals were immunised with S-antigen 


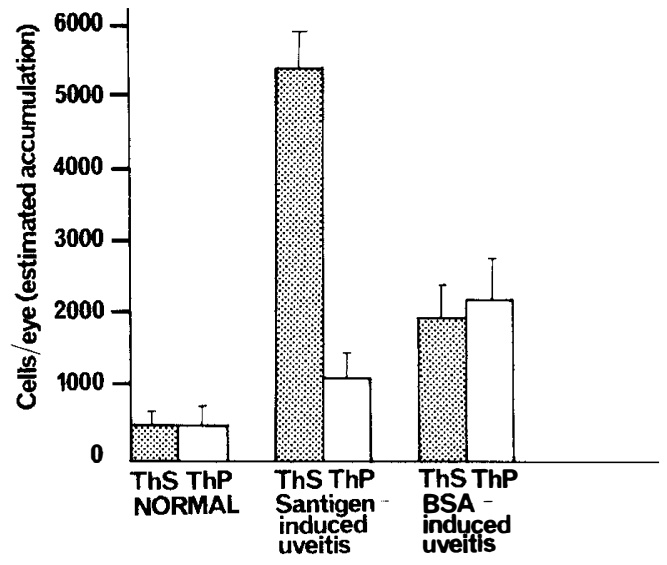

Fig. 2. Estimated accumulation of labelled T-cells after $24 \mathrm{hrs}$ in eyes of normal rats and rats with $S$ antigen or BSA induced uveitis. ThS $=\mathrm{S}$-antigen specific $\mathrm{T}$-cell line. ThP $=$ PPD specific $\mathrm{T}$-cell line

and left for 11 days, at which time most of the eyes were visibly inflamed. On day 11, labelled ThS or ThP were injected intravenously into these rats. The animals were sacrificed after 24 hours and the eyes removed. The eyes were put into formaldehyde prior to counting and were later examined histologically to ensure that inflammation had occurred. In eight out of the 10 animals, both eyes were severely inflamed but two animals did not develop the disease. The results from these two animals were excluded. Figure 2 shows the estimated accumulation of cells in the eye in EAU, both for ThS $(n=8$ eyes) and for ThP ( $n=8$ eyes). Both types of $T$ cells accumulated in these inflamed eyes to a greater extent than in control eyes after 24 hours, with ThS accumulating to a much greater extent than ThP.

\section{Retention of ThS and ThP in BSA uveitis:}

Nine animals were immunised with soluble BSA in CFA and challenged in the right eye with soluble BSA and in the left eye with saline on day 10 . On day 11 , post-immunisation all right eyes became obviously and severely inflamed and all the left eyes remained normal. At this point, the animals were given labelled ThS or ThP cells IV and sacrificed 24 hours later. Figure 2 shows the calculated accumulation obtained in these animals for ThS ( $n=5$ eyes) and ThP $(n=4$ eyes) in both the right eyes (inflamed) and the left eyes (injected with saline but uninflamed), in comparison to control (normal) eyes. Accumulation of $\mathrm{ThS}$ and $\mathrm{ThP}$ in the inflamed eyes occurred to a similar extent, and was greater than the accumulation in control eyes after 24 hours.

\section{Discussion}

These results demonstrate that circulating $\mathrm{T}$ cells recognising ocular antigens, can be specifically retained in the inflamed eye when the retinal vascular endothelium aberrantly expresses class II MHC antigens. There was increased access for ocular specific and nonspecific T-cells in the inflamed eye as compared to the uninflamed eye but inflammation in the absence of Ia expression by the RVE did not result in the specific accumulation of ocular antigen-specific T-cells. It has been suggested that expression of Ia by endothelial cells could be used to recruit and activate circulating autoantigen-specific $T$ helper cells into the site of a developing immune response ${ }^{25}$ such a process could be involved in either the initiation or potentiation of the autoimmune process in the eye.

In both types of inflammation examined, T-cells are found infiltrating the eye and several tissues are known to become $\mathrm{Ia}+{ }^{19,20,21}$ Interferon-gamma (one of many lymphokines secreted by activated T-cells) has been found to induce Class II expression by a variety of cell types and strong surface expression of Class II antigens was demonstrable by cultured normal human thyrocytes after incubation with interferon-gamma for $24 \mathrm{hrs}$ at physiological doses. ${ }^{26}$ The production of this lymphokine by activated autoreactive T-cells infiltrating the eye would enable the spread of Class II expression within the tissues of the eye and propagation of the autoimmune process. Viruses have also been shown to directly induce Class II expression and it has been suggested that viruses may be involved in the initiation of autoimmune processes..$^{27,28}$

Other tissues within the eye which can be induced to express Ia antigens in the inflammatory process include the ciliary body epithelium and the retinal pigment 
epithelium. However, it is likely that neither of these tissues are important in attracting circulating autoreactive T-cells since as Ia expression by these tissues occurred in both types of inflammation, it would not account for the differential accumulation of the two $\mathrm{T}$-cell lines. Why some cells in a given tissue express Ia and others do not is unclear. The response of cells to interferon-gamma can be inhibited by various molecules in the blood such as prostaglandin $\mathrm{E}$ and glucocorticoids ${ }^{29}$ and the concentration of these substances may vary in different locations in the eye.

The significance of Ia expression by different parts of the eye is unclear. It may be that the expression of Ia antigens serves different functions in different tissues. The RVE may be important in the binding and directing of autoreactive $T$ cells and the other tissues may be involved in the presentation of local ocular antigens to these $T$ cells. The question of whether Ia + cells can present self-antigens is important. Autoimmunity may be controlled by limiting Ia + expression to a very few cells thus controlling the expression of self-antigens. Once Ia + is expressed in non-lymphoid cells there is the potential for them to present autologous antigens and trigger an autoimmune response. ${ }^{5}$

In ocular inflammation induced with the non-ocular antigen BSA, both $\mathrm{T}$ cell lines showed increased accumulation in the inflamed, over the non-inflamed eyes. The severe inflammatory process, however induced, is likely to result in the breakdown of the blood-ocular barriers and hence a generalised increased access for cells of all types from the blood-stream.

In conclusion, a mechanism exists which could result in the specific retention and activation of the few circulating ocular autoreactive T-cells. Once in the eye, these activated T-cells could secrete many lymphokines including interferon-gamma which would then result in the aberrant expression of class II MHC antigens by several tissues within the eye and the presentation of local antigens to T-cells. Other lymphokines would attract more T-cells and other cell types including neutrophils and macrophages and result in further damage to the ocular tissues. Once the retinal vascular endothelium becomes
$\mathrm{Ia}+$, for whatever reason be it inflammatory, virus infection or as a result of circulating interferon-gamma from immune processes in other tissues, autoreactive T-cell have access to the eye and can initiate or perpetuate inflammatory processes within the eye. More work now needs to be done on human ocular tissues and on ways of suppressing class II antigen expression by tissues in the eye.

\section{References}

${ }^{1}$ Bottazzo G., Todd I, Mirakiai R. et al. Organspecific autoimmunity: A 1986 overview. Immunol Rev 1986; 94: 137-69.

${ }^{2}$ Leder P. The genetics of antibody diversity. Scientific American 1982; 246: 72-83.

${ }^{3}$ Cohen I. and Wekerle H. Autoimmunity, self recognition and blocking factors. In Talal $\mathbf{N}$. ed. Autoimmunity: Genetic, immunologic, virologic and clinical aspects. New York: Academic Press 1977: 231-275.

${ }^{4}$ Guilbert B., Dighiew G. Avrameus S. Naturally occurring antibodies against nine common antigens in normal humans. J Immunol 1982; 28: $2779-87$.

${ }^{5}$ Bottazzo G., Pujol-Borrell R., Hanafusa T. et al. Role of aberrant HLA-DR expression and antigen presentation in induction of endocrine autoimmunity. Lancet 1983; ii: 1115-9.

${ }^{6}$ Hammerling G. Tissue distribution of Ia antigens and their expression on lymphocyte subpopulations. Transplant Rev 1976; 30: 64-82.

${ }^{7}$ Unanue $\mathrm{E}$. The regulatory role of macrophages in antigenic stimulation. II. Symbiotic relationship between lymphocytes and macrophages. Adv Immunol 1981; 31: 1-32.

8 Wiman K., Curman B., Forsum U. et al. Occurrence of Ia antigen on tissues of nonlymphoid origin. Nature 1978; 276: 711-13.

${ }^{9}$ Hanafusa T., Pujol-Borrell R., Chiovato L. et al. Aberrant expression of HLA-DR antigen on thyrocytes in Graves' disease: relevance for autoimmunity. Lancet ii 1983 1111-5.

10 Wagner C., Vetto M. Burge D. The mechanism of antigen presentation by endothelial cells. Immunobiol 1984; 168: 452-63.

${ }^{11}$ Londei M., Bottazzo G. Feldman M. Human Tcell clones from autoimmune thyroid glands: specific recognition of autologous thyroid cells. Science 1985; 228: 85-9.

${ }^{12}$ Chan C., Detrick B., Nussenblatt R. et al. HLADR antigens on RPE cells from patients with uveitis. Arch Ophthalmol 1986; 104: 725-9.

13 Detrick M., Rodrigues M., Chan C. et al. Expression of HLA-DR antigen on RPE cells 
in retinitis pigmentosa. Am J Ophthalmol 1986; 101: 584-90.

${ }^{14}$ Pfister C., Chabre M., Pluet J. et al. Retinal Santigen identified as the $48 \mathrm{~K}$ protein regulating light dependent phosphodiesterase in rods. Science 1985; 228: 891-3.

15 Faure J. Autoimmunity and the retina. Curr Top Eye Res. 1980; 2: 215-302.

16 de Kozak Y., Sakai J., Thillaye B. et al. S-antigen induced EAU in rats. Curr Eye Res. 1981; 1: 327-332.

${ }^{17}$ Mochizuki M., Kuwabara T., McCallister C. et al. Adoptive transfer of EAU in rats. Invest Ophthalmol Vis Sci 1985; 26: 1-9.

${ }^{18}$ Caspi R., Roberge F., McCalister c. et al. T-cell lines mediating EAU in the rat. $J$ Immunol 1986; 136: 928-33.

${ }^{19}$ Fujikawa L., Chan C, McCallister C. et al. Activation of endothelial cells in EAU expressed by the appearance of fibronectin and the Ia antigen. Invest Ophthalmol vis Sci 1985; 26: 97.

${ }^{20}$ Chan C., Hooks J., Nussenblatt R. et al. Expression of Ia antigen on RPE in EAU. Curr Eye Res 1986; 5: 325-30.

21 Lightman S., Palestine A. Nussenblatt R. Immunohistopathology of experimental uveitis induced by a non-ocular antigen. Curr Eye Res 1986; 5: 857-62.

${ }^{22}$ Lightman S., Palestine A. and Nussenblatt R. Intraocular Ia expression in vivo induced in the absence of immune T-cells. Cell Immunol 1987; 106: 242-9.

${ }^{23}$ Dorey C., Cozette J. Faure J. A simple and rapid method for isolation of retinal S-antigen. Ophthalmic Res 1982; 14: 249-55.

${ }^{24}$ Naparstek Y., Ben-Nun A., Holoshitz J. et al. T lymphocyte lines producing or vaccinating against autoimmune encephalomyelitis (EAE). Functional activation induces peanut agglutinin receptors and accumulation in the brain and thymus of line cells. Eur J Immunol 1983; 13: 418-23.

${ }^{25}$ Pober J., Collins T., Gimbourne M. et al. Inducible expression of class II MHC antigens and the immunogenicity of vascular endothelium. Transplantation 1986; 41: 141-6.

26 Todd I., Pujol-Borrell R., Hannad L. et al. Interferon-gamma induces HLA-DR expression by thyroid epithelium. Clin Exp Immunol 1985; 61: 265-73.

${ }^{27}$ Belfiore A., Pujol-Borrell R., Manerhoff T. et al. Effect of SV-40 transformation on HLA expression by thyroid follicular cells: a rise of a population of DR positive thyrocytes. Ann d'Endrocrinol 1987; 47: 17.

${ }^{28}$ Massa P., Domies R. and ter Meulen V. Viral particles induce Ia antigen expression on astrocytes. Nature 1986; 320: 543-6.

${ }^{29}$ Unanue E. Antigen-presenting function of the macrophage. Ann Rev Immunol 1984; 2 395428. 